\title{
FTIR and Raman spectroscopy characterization of fluorine-bearing titanian clinohumite in antigorite serpentinite and chlorite harzburgite
}

\author{
Kenneth T Koga ${ }^{1,2,3^{*}}$, Carlos J Garrido ${ }^{4}$, José A Padrón-Navarta ${ }^{5}$, Vicente López Sánchez-Vizcaíno ${ }^{6}$ \\ and María T Gómez-Pugnaire ${ }^{7}$
}

\begin{abstract}
Titanian clinohumite is an accessory phase found in peridotites, and it can be a key repository of volatile and other trace elements in sub-arc mantle. To characterize spectroscopic variations due to volatile elements in the phase, we have investigated the infrared spectroscopic characteristics of a suite of naturally occurring Ti clinohumite minerals with varying $\mathrm{F}$ and $\mathrm{Ti}$ concentrations. Samples were ultramafic rocks from Cerro del Almirez, Spain and Cima di Gagnone, Switzerland. The infrared spectra corresponding to $\mathrm{OH}$ vibrations showed systematic variation in regard to the abundance of $\mathrm{F}$ in Ti clinohumite. In particular, the intensity ratios of infrared absorption spectra at 3,565 and $3,390 \mathrm{~cm}^{-1}$ correlated linearly with the abundance of $\mathrm{F}$ independently of the crystal orientation. Raman spectra did not corroborate the Fourier transform infrared (FTIR) results. This intensity ratio provides an alternative analytical criterion for the characterization of Ti clinohumite.
\end{abstract}

\section{Findings Introduction}

Titanian clinohumite (TiChu) is a member of the humite group minerals that constitute a polysomatic series with olivine (Thompson 1978; Veblen 1991, 1992). The generalized mineral formula of humite group minerals is

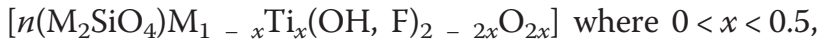
$\mathrm{M}$ represents divalent cations (mostly $\mathrm{Mg}$ with minor Fe, $\mathrm{Mn}$, and $\mathrm{Ni}$ ), and $n$ is one for norbergite, two for chondrodite, three for humite, and four for clinohumite. Clinohumite is the humite group mineral whose crystal structure is most closely related to olivine because it has the highest proportion of filled tetrahedral sites.

TiChu is a common accessory mineral in hydrous ultrabasic rocks including antigorite serpentinite (Damour 1879; Brugnatelli 1904; De Quervain 1938; Bearth 1967; Möckel 1969; Trommsdorff and Evans 1980), metaperidotite from high-pressure metamorphic terrains (Möckel

\footnotetext{
* Correspondence: k.koga@opgc.univ-bpclermont.fr

'Laboratoire Magmas et Volcans, Clermont Université, Université Blaise

Pascal, Clermont-Ferrand 63038, France

'Laboratoire Magmas et Volcans, CNRS UMR 6524, Clermont-Ferrand 63038, France

Full list of author information is available at the end of the article
}

1969; Evans and Trommsdorff 1983; López SánchezVizcaíno et al. 2005), and kimberlite xenoliths (McGetchin and Silver 1970; Matsyuk and Langer 2004). Despite its accessory character, TiChu is thought to play an important role in the storage of water (McGetchin and Silver 1970), fluorine (Engi and Lindsley 1980), boron and lithium (Scambelluri et al. 2004), and the high field strength elements $\mathrm{Nb}$ and $\mathrm{Ta}$ (Scambelluri et al. 2001; Garrido et al. 2005) in upper mantle ultrabasic rocks. Furthermore, natural mantle olivine usually contains TiChu as defects and patches (Kitamura et al. 1987; Wirth et al. 2001; Berry et al. 2005; Mosenfelder et al. 2006a, 2006b), which may be an effective mechanism for incorporating hydrogen into this nominally anhydrous mantle mineral (Wirth et al. 2001; Berry et al. 2005; Mosenfelder et al. 2006b).

The OH/F ratio of TiChu plays a particularly important role in the stabilization of TiChu at high temperature (Engi and Lindsley 1980; Trommsdorff and Evans 1980; Evans and Trommsdorff 1983), and it is crucial for its stabilization at mantle temperatures beyond the antigorite stability field in hydrous ultrabasic systems (Engi and Lindsley 1980; Trommsdorff and Evans 1980). This is possibly due to the effect of the $\mathrm{OHF}_{-1}$ substitution that reduces the repulsion of $\mathrm{H}-\mathrm{H}$ bonds within the brucite 
layers of the clinohumite crystal structure (Fujino and Takeuchi 1978; Ribbe 1979). Because of its potential role as a repository phase for $\mathrm{H}, \mathrm{F}$, and $\mathrm{Ti}$ in ultramafic rocks, characterizations of naturally occurring TiChu can provide greater insight into fluid transport in subduction zones.

TiChu is one of the trace minerals in ultramafic lithologies that is often overlooked because its submicroscopic intergrowth with olivine can easily be missed during electron microprobe analysis and its geochemical significance has only recently been discovered. We present a Fourier transform infrared (FTIR) transmittance of TiChu with variable $\mathrm{OH} / \mathrm{F}$ ratios from high-pressure hydrous ultramafic rocks. Previous spectroscopic studies of natural clinohumite are scarce (Miller et al. 1987; Matsyuk and Langer 2004; Berry et al. 2005; Hermann et al. 2007) and have not explored the potential effect of the compositional variation in this mineral in detail. We found that the FTIR spectrum of natural clinohumite in the range of the $\mathrm{OH}$ absorbance bands $(3,800$ to $3,200 \mathrm{~cm}^{-1}$ ) systematically changes with the $\mathrm{OH} / \mathrm{F}$ ratio. Combined with wavelength-dispersive X-ray spectroscopy (WDS) electron microprobe data, we propose a calibration that quantitatively correlates the absorbance spectrum with the $\mathrm{OH} / \mathrm{F}$ ratio for this mineral. This calibration gives an alternative assessment of $\mathrm{OH}-\mathrm{F}$ substitutions in TiChu by FTIR, which is probably most applicable to inclusions in minerals and fine grains in experimental changes.

\section{Sample location and petrography}

We analyzed a wide variety of petrographic types of TiChu from the Cerro del Almirez ultramafic body, Spain. López Sánchez-Vizcaíno et al. (2005) provided a detailed account of the petrology of TiChu in this massif. Our samples can be divided into: TiChu associated with antigorite serpentinite (atg-serpentinite), chlorite harzburgite (chl-harzburgite), and enstatite-rich veins within chl-harzburgite. TiChu associated with atg-serpentinite is almost fluorine free and occurs as dispersed grains embedded in a matrix of flaky antigorite (type serp-1; Al96-20), as veins with millimeter- to centimeter-sized agglomerations of TiChu and olivine (type serp-2; Al96-15B), and as rare small grains formed together with chlorite after relic Ti-rich clinopyroxene grains (type serp-3; Al96-20). TiChu associated with chl-harzburgite is exclusively F-OH$\mathrm{TiChu}$ and occurs as single grains in the matrix of chlharzburgite minerals (type hz-1; Al96-10), as rare patches, intergrowths, and lamellae within olivine (type hz-2), and as individual grains within enstatite-chlorite veins (type hz-3; Al01-7B). We also studied a third textural type occurring in carbonate-rich lenses near the contact with the country rock. These samples display a 'sunny-side up' texture characterized by yellow cores of F-rich TiChu sequentially rimmed by light yellow and then clear olivine (type 4; Al98-29A).
In addition, we analyzed three fluorine-bearing TiChu samples from a garnet metaperidotite in an ultramafic lens enclosed in kyanite schist from the Cima di Gagnone (Central Alps, Ticino, Switzerland). These samples have already been described by Evans and Trommsdorff (1983) (all are from locality 304; samples MG-304-B). TiChu grains occur here in brown patches within a matrix of olivine, orthopyroxene, and spherical aggregates of chlorite interpreted as breakdown products from garnet. These TiChu samples expand the compositional range of TiChu investigated here to low $\mathrm{OH} / \mathrm{F}$ and $\mathrm{X}_{\mathrm{Ti}}$ compositions.

\section{Analytical methods \\ Electron microprobe analysis}

Major elemental compositions of TiChu were measured on the same spots from which FTIR spectra were collected; this was done using a SX-100 CAMECA electron microprobe (EMP) at the Laboratoire Magmas et Volcans (Clermont-Ferrand, France) with a $15-\mathrm{kV}$ accelerating voltage, a 30-nA sample current, and a counting time ranging from 10 to $30 \mathrm{~s}$ using thallium acid phthalate (TAP), and pentaerythritol (PET) refraction crystals. Fluorine analyses were performed following the procedure of Moune et al. (2007) but modified to a 40-nA sample current and 30-s acquisition time using three TAP crystals. Fluorine concentrations were determined using $\mathrm{CaF}_{2}$ calibration standards. The estimated precision of $\mathrm{F}$ depended on the concentrations and ranged from $2 \%$ to $32 \%$ relative deviation in repeated analyses. The detection limit was $300 \mathrm{ppm}$ or lower.

\section{FTIR sample preparation and measurements}

Micro-FTIR spectroscopy analyses were made on doublesided polished sample slabs prepared on glass slides with Crystalbond $^{\mathrm{m}}$ that were subsequently dissolved off with acetone and then rinsed thoroughly with ethanol. For spectral calibration, we measured the slab thickness with a micrometer, and the value had a precision of $\pm 5 \mu \mathrm{m}$.

We collected in situ FTIR spectra using a Bruker ${ }^{\text {tm }}$ HYPERION microscope at the Laboratoire Magmas et Volcans, Université Blaise-Pascal (Clermont-Ferrand, France). The FTIR spectra were acquired using the Video Assisted Measure option of the Bruker ${ }^{\mathrm{m}}$ OPUS software (v. 5.0). For each spot, we acquired one spectrum in unpolarized infrared (IR) light and two spectra in polarized IR light taken at orthogonal orientations corresponding to maximum and minimum pleochroism under polarized light. The IR polarizer was gold-coated thallium bromide iodide, and it had $87 \%$ polarization efficiency. The IR source was a mid-IR lamp, and a KBr beam splitter was used. Spectra were collected with $a \times 15$ IR objective and a nitrogen-cooled mercury cadmium telluride (MCT) detector, and the values were calculated over the range of 4,000 to $700 \mathrm{~cm}^{-1}$ at $4 \mathrm{~cm}^{-1}$ resolution 
by averaging 100 scans. The spot sizes were adjusted from $50 \times 50$ to $30 \times 30 \mu \mathrm{m}$ square areas to measure an optically clear, homogenous part of crystal. Every sample measurement consisted of a background measurement followed by acquisition of spectra from several grains.

\section{Raman spectroscopy}

Laser Raman measurements on the same samples were acquired at the Ecole Normale Supérieur (ENS), in Lyon, France using a Jobin-Yvon LabRam HR800 spectrometer equipped with a charge-coupled device (CCD) detector. An argon ion laser from Spectra Physics, which was set at a wavelength of $632.8 \mathrm{~nm}$, was used to excite Raman scattering. Final spectra were obtained by averaging three spectra with an acquisition time of $30 \mathrm{~s}$ for shift ranges of 500 to $2,000 \mathrm{~cm}^{-1}$ (aluminosilicate framework domain, TOT) and 3,200 to $3,800 \mathrm{~cm}^{-1}(\mathrm{OH}$ stretching domain) relative to the laser light wavelength.

\section{Results}

\section{Compositional variations of titanian clinohumite}

Table 1 shows the composition of TiChu samples used in this study. An averaged value for each sample is reported although not every crystal in a sample is necessarily homogenous. The degree of heterogeneity was inferred from the standard deviations. For example, because the analytical uncertainty of $\mathrm{FeO}$ is approximately \pm 0.5 wt.\%, the standard deviation of a homogeneous sample should give roughly the same value. Thus, larger variations of $\mathrm{MgO}, \mathrm{FeO}$, and $\mathrm{TiO}_{2}$ in samples Al96-20 and Al98$29 \mathrm{~A}$ were due to the compositional heterogeneity. The analytical spots for FTIR, Raman, and the electron microprobe were all at the same coordinates and identified by the sample textures. The correlations of FTIR spectra and TiChu compositions were established from the analyses for each point rather than averaged sample compositions.

Figure 1 shows notable compositional variation due to exchange vectors. The mole fractions of $\mathrm{F}$ and $\mathrm{Ti}$ in their respective crystallographic sites formed a negative correlation. This has been described elsewhere as being the result of the exchange vectors of $\mathrm{OH}-\mathrm{F}$ and $\mathrm{TiO}_{2}-\mathrm{M}(\mathrm{OH})_{2}$ (Evans and Trommsdorff 1983). Our samples showed a coherent variation that corresponds to these exchange vectors. Consequently, F-rich TiChu is $\mathrm{OH}$ and $\mathrm{Ti}$ poor, and vice versa.

\section{FTIR spectra}

Figure 2 shows a series of unpolarized Ti-clinohumite spectra. Here, we focus on the spectrum wavenumbers

Table 1 Titanian clinohumite from Cerro del Almirez, Spain (AI) and Cima di Gagnone, Switzerland (MG)

\begin{tabular}{|c|c|c|c|c|c|c|c|c|c|c|c|c|c|c|}
\hline \multirow[b]{3}{*}{$\mathrm{SiO}_{2}$} & \multicolumn{14}{|c|}{ Sample: rock type } \\
\hline & \multicolumn{2}{|c|}{$\begin{array}{l}\text { Al96-20: Ant } \\
\text { serp }\end{array}$} & \multicolumn{2}{|c|}{$\begin{array}{l}\text { Al96-15B: TiCl vein } \\
\text { Serp }\end{array}$} & \multicolumn{2}{|c|}{$\begin{array}{l}\text { Al96-10: Px } \\
\text { lamella }\end{array}$} & \multicolumn{2}{|c|}{$\begin{array}{l}\text { Al96-1C: Chl } \\
\text { harz }\end{array}$} & \multicolumn{2}{|c|}{$\begin{array}{l}\text { Al01-7B: En } \\
\text { vein }\end{array}$} & \multicolumn{2}{|c|}{$\begin{array}{l}\text { Al98-29A: } \\
\text { Marble }\end{array}$} & \multicolumn{2}{|c|}{$\begin{array}{l}\text { MG-304B: Chl } \\
\text { perid }\end{array}$} \\
\hline & 35.8 & (9) & 36.4 & (5) & 36.8 & (1) & 36.2 & (2) & 36.9 & (4) & 36.8 & (4) & 36.2 & (4) \\
\hline $\mathrm{TiO}_{2}$ & 5.4 & (1) & 5.3 & (2) & 5.6 & (2) & 4.9 & (1) & 4.8 & (1) & 2.4 & (1.1) & 1.9 & (6) \\
\hline $\mathrm{FeO}$ & 7.1 & (2) & 8.7 & (5) & 8.1 & (6) & 8.3 & (1) & 8.9 & (2) & 9.1 & (8) & 8.4 & (3) \\
\hline $\mathrm{MnO}$ & 0.36 & (4) & 0.32 & (3) & 0.39 & (3) & 0.13 & (2) & 0.10 & (5) & 0.10 & (3) & 0.08 & (4) \\
\hline $\mathrm{MgO}$ & 47.8 & $(1.2)$ & 47.3 & (5) & 47.6 & (4) & 47.7 & (2) & 48.1 & (3) & 49.4 & (1.0) & 49.8 & (4) \\
\hline $\mathrm{NiO}$ & 0.14 & (3) & 0.16 & (1) & 0.15 & (2) & 0.25 & (1) & 0.19 & (1) & 0.19 & (1) & 0.14 & $(2)$ \\
\hline $\mathrm{F}$ & 0.02 & $(2)^{c}$ & 0.02 & $(2)^{c}$ & 0.014 & $(4)^{d}$ & 0.49 & (5) & 0.62 & (4) & 1.58 & (50) & 1.78 & (21) \\
\hline $\mathrm{H}_{2} \mathrm{O}^{\mathrm{a}}$ & 2.71 & (26) & 2.73 & (2) & 2.74 & (2) & 2.50 & (2) & 2.47 & (3) & 2.02 & (23) & 1.91 & (10) \\
\hline Total & 99.6 & (8) & 101.0 & (5) & 101.5 & (3) & 100.8 & (4) & 102.1 & (6) & 101.6 & (3) & 100.4 & (5) \\
\hline$n$ & 4 & & 16 & & 5 & & 5 & & 4 & & 8 & & 5 & \\
\hline $\mathrm{Ti}$ & 0.45 & (19) & 0.43 & (2) & 0.46 & (1) & 0.41 & (1) & 0.39 & (1) & 0.20 & (9) & 0.16 & (5) \\
\hline $\mathrm{Fe}$ & 0.66 & (7) & 0.80 & (4) & 0.74 & (6) & 0.76 & (1) & 0.81 & (1) & 0.82 & (7) & 0.76 & (3) \\
\hline $\mathrm{Mn}$ & 0.03 & (2) & 0.03 & (0) & 0.04 & (0) & 0.01 & (0) & 0.01 & (0) & 0.01 & (0) & 0.01 & (0) \\
\hline $\mathrm{Mg}$ & 7.87 & (64) & 7.73 & (6) & 7.74 & (5) & 7.80 & (1) & 7.77 & (1) & 7.97 & (12) & 8.10 & (5) \\
\hline $\mathrm{Ni}$ & 0.01 & (2) & 0.01 & (0) & 0.01 & (0) & 0.02 & (0) & 0.02 & (0) & 0.02 & (0) & 0.01 & $(0)$ \\
\hline $\mathrm{F}$ & 0.005 & (10) & 0.006 & (10) & 0.009 & (10) & 0.17 & (2) & 0.21 & (1) & 0.54 & (17) & 0.61 & (7) \\
\hline $\mathrm{OH}^{\mathrm{b}}$ & 1.10 & (32) & 1.12 & (3) & 1.07 & (3) & 1.02 & (3) & 1.01 & (2) & 1.07 & (5) & 1.08 & (3) \\
\hline
\end{tabular}

$\mathrm{TiCl}$ compositions are an average of several electron probe analyses on a rock sample shown as weight percent, and the number of points used for the average is indicated as ' $n$.' Large standard deviations of the average represent the extent of sample heterogeneity, as indicated by italics. Numbers in parentheses indicate the uncertainty expressed as the last digits of reported values, as in ' 1.07 (5)' corresponds to $1.07 \pm 0.05$. ${ }^{a} \mathrm{H}_{2} \mathrm{O}$ weight percent was calculated from the stoichiometric balance of $\mathrm{OH} .{ }^{b} \mathrm{OH}$ was calculated from the stoichiometric balance. ${ }^{c}$ Three low $\mathrm{F}$ abundance measurements were below the detection limit and the relative standard deviations were more than $100 \%$; hence, these values should be considered as maximum possible values. ${ }^{\mathrm{d}}$ The value verified by a secondary ion mass spectrometer. 


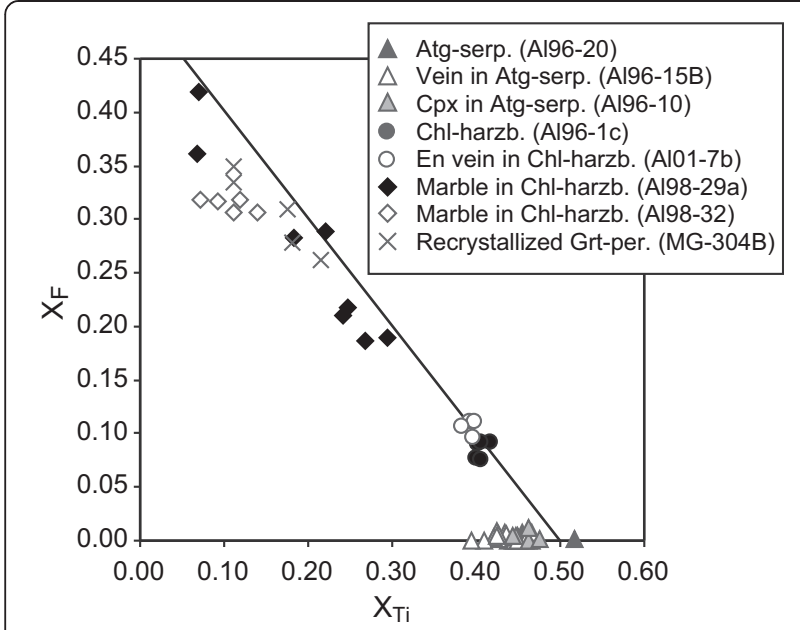

Figure 1 Plot of $\boldsymbol{X}_{\mathrm{F}}$ versus $X_{\mathrm{Ti}}$. It shows TiChu's F-OH exchange reaction follows a compositional vector $\mathrm{TiO}_{2} \mathrm{Mg}_{-1} \mathrm{~F}_{-2}$. $X_{\mathrm{F}}$ is $\mathrm{F} /(\mathrm{F}+\mathrm{OH})$ in moles. $X_{\mathrm{Ti}}$ is the fraction of $\mathrm{Ti}$ in the Mg-site.

between 3,700 and $3,250 \mathrm{~cm}^{-1}$ that correspond to the absorbance bands of hydroxyl groups. Spectra were baseline-corrected and normalized to 1-cm thickness. The shape of the spectra and the relative strength of the bands varied significantly for F-rich and F-poor TiChu (Figure 2). The spectra of all investigated F-poor TiChu are characterized by two weak bands at 3,565 and $3,528 \mathrm{~cm}^{-1}$ of similar strength (typically between 2 to 7 absorbance units), and a stronger, wider band between 3,415 and $3,394 \mathrm{~cm}^{-1}$ with a shoulder at lower wavenumbers. For example, the strong band at $3,390 \mathrm{~cm}^{-1}$ was present in all spectra from the F-rich to F-poor clinohumites. This spectrum is similar to those described

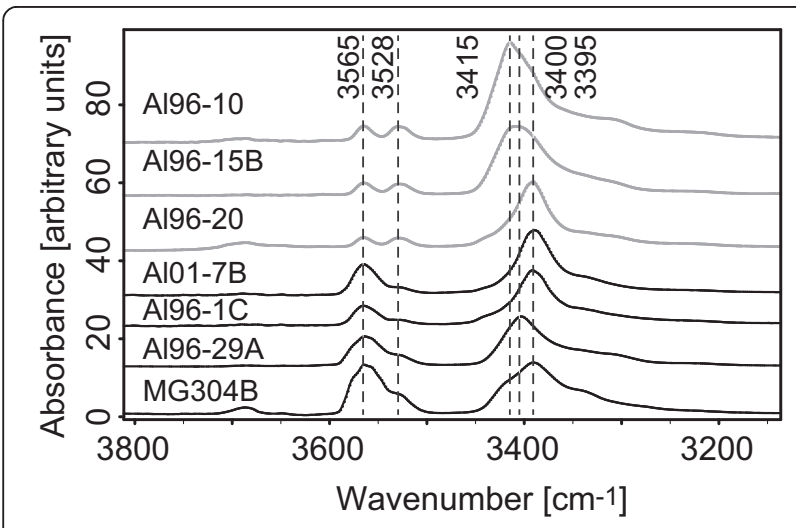

Figure 2 FTIR spectra showing the characteristic TiChu OH bands. Fluorine concentration increases towards the lower spectra. As F increases, the relative heights of 3,565 and 3,528 change, as well as the height of the large peaks around 3,400 to 3,390. From these observations, at a first order, F-rich and F-poor TiChu are easily identified by their FTIR spectra in $\mathrm{OH}$ regions. For clarity, the spectra are ordinate-shifted. elsewhere (Kitamura et al. 1987; Miller et al. 1987; Kurosawa et al. 1997; Berry et al. 2005; Matsyuk and Langer 2004). We did not observe the broad $3,840 \mathrm{~cm}^{-1}$ band reportedly present in a high F clinohumite (SatishKumar and Niimi 1998).

The shape of the spectra was largely orientation independent (Figure 3). The similarity of the shape implies constant relative peak heights, although there may be significant changes in absorption. However, closer inspection of the relative heights of the stronger bands at 3,415 and $3,394 \mathrm{~cm}^{-1}$ showed that they were dependent on crystal orientation as there were more prominent shoulders in stronger spectra. On the contrary, the wavenumbers for the weaker bands at 3,565 and $3,528 \mathrm{~cm}^{-1}$ remained constant, but their relative height varied slightly with orientation.

The spectrum of F-rich TiChu was characterized by the $3,565 \mathrm{~cm}^{-1}$ band being more intense than the $3,528 \mathrm{~cm}^{-1}$ band. The $3,528 \mathrm{~cm}^{-1}$ band was weaker than that of the $3,565 \mathrm{~cm}^{-1}$ band for F-poor specimens, and the exact peak position was obscured by the larger $3,565 \mathrm{~cm}^{-1}$ band (Figure 2, sample MG304B). In this case, deconvolution of the spectra from 3,570 to $3,520 \mathrm{~cm}^{-1}$ identified the presence of the $3,528 \mathrm{~cm}^{-1}$ band. These results indicate that the shape of TiChu spectra depends on its composition, and the intensity ratio of the 3,565 to $3,528 \mathrm{~cm}^{-1}$ peaks appears to be sensitive to the $\mathrm{F} / \mathrm{OH}$ ratio (Figure 2).

\section{Laser micro-Raman spectroscopy}

Figure 4 shows the laser micro-Raman spectra for TiChu with variable $\mathrm{F}$ content. The spectra were similar for all samples and displayed Raman bands characteristic of TiChu in the aluminosilicate framework domain (500 to $1,100 \mathrm{~cm}^{-1}$, Figure 4a; Frost et al. 2007). However, we

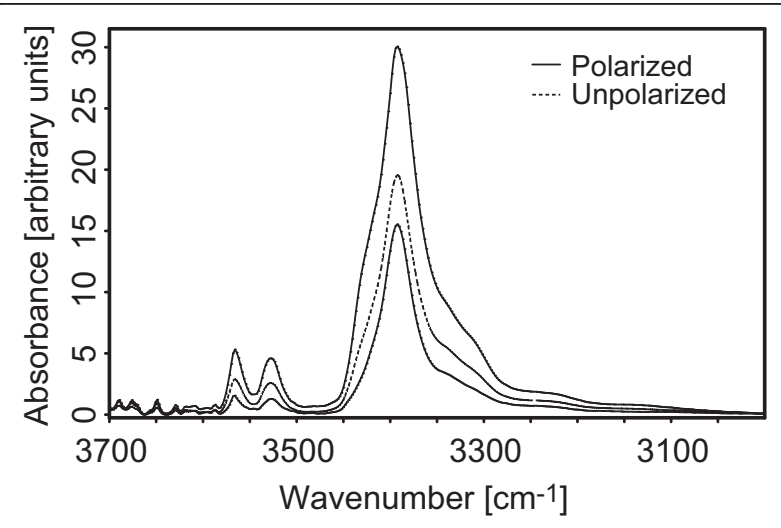

Figure 3 Two polarized and one unpolarized spectra of TiChu. General similarities of the spectra are noticeable, although subtle variations of relative peak heights are also present, which indicates that some infrared (IR) absorbers are not parallel. 

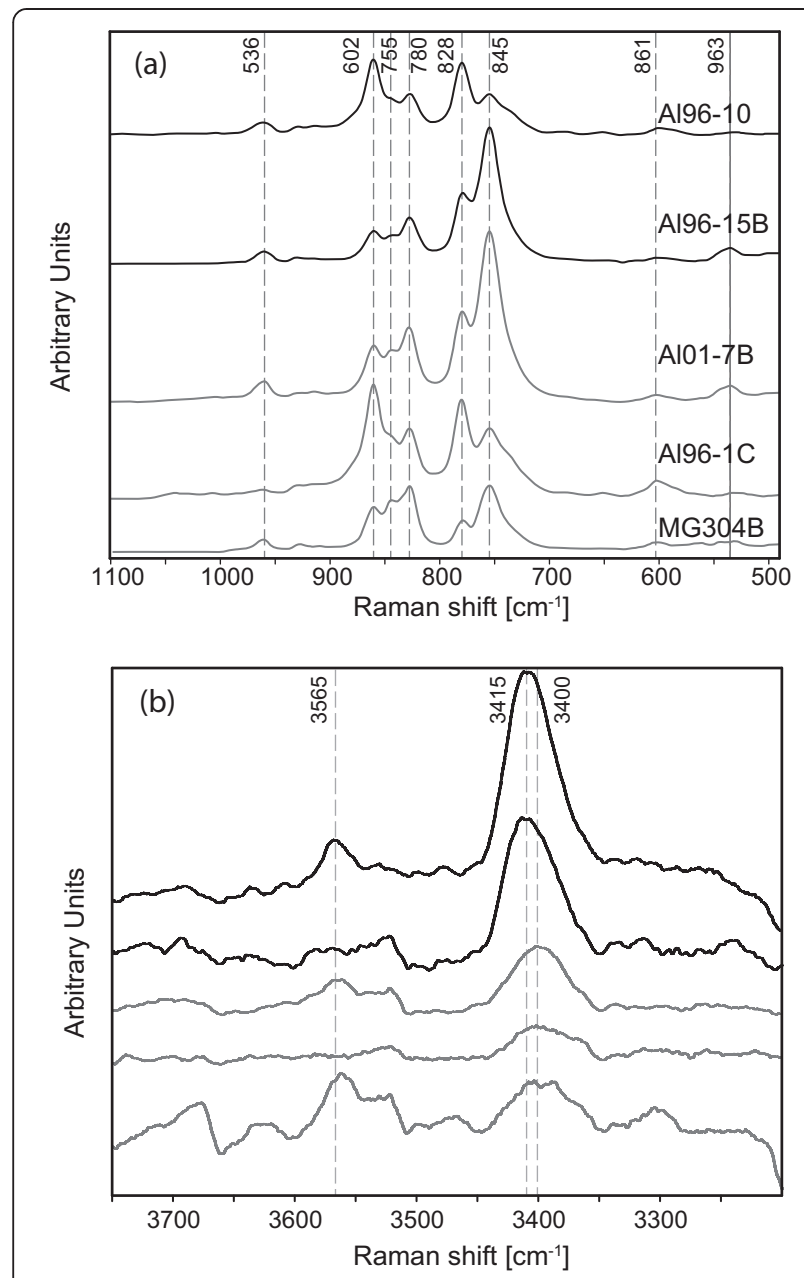

Figure 4 Raman spectra of TiChu with varying F content. Here, (a) low- and (b) high-frequency regions of TiChu Raman signals show identical peak positions (at 536, 602, 755, 780, 828, 845, 861, and 963). Variations of their shapes and relative heights are due to crystal orientations. While Raman spectra are useful to identify microinclusions and intergrowth of TiChu, they do not provide obvious indications of compositional variations. The order of spectra is the same for both figures.

did not detect many of the reported weak bands, which was probably a result of the weak excitation laser used in this study. In particular, our Raman observation in the $\mathrm{OH}$ band region differed significantly from that of Frost et al. (2007), who described several peaks of Raman shift in the region of 3,527 to $3,578 \mathrm{~cm}^{-1}$, whereas we detected a weak band at $3,565 \mathrm{~cm}^{-1}$. The IR absorption peaks corresponded to all the reported $\mathrm{OH}$ Raman bands. We did not detect a clear variation in the locations of low-frequency Raman bands among clinohumites with variable $\mathrm{OH} / \mathrm{F}$ ratios (Figure 4a). All clinohumites showed a band at 3,412 to $3,398 \mathrm{~cm}^{-1}$ with variable strength in the $\mathrm{OH}$ stretching domain $\left(3,200\right.$ to $3,750 \mathrm{~cm}^{-1}$, Figure $\left.4 \mathrm{~b}\right)$. The strength of the band is probably related to the $\mathrm{OH} / \mathrm{F}$ ratio and orientation of the sample. The peak was well developed in the F-poor samples; F-rich samples lost their 3,200 to $3,750 \mathrm{~cm}^{-1}$ Raman signal, which is consistent with the lower $\mathrm{OH}$ abundance.

\section{Discussion}

\section{Orientation-independent spectral shapes}

For crystalline material (except for that with cubic symmetry), polarized spectra normally vary in intensity depending on the orientation of the crystal with respect to the photon vibration vector. This type of behavior is also expected for TiChu, which is orthorhombic. However, the polarized IR spectra of orthogonal orientations, which were collected on randomly oriented Ti-clinohumite crystals, showed a general similarity in shape. Specifically, it should be noted that relative heights of some peaks were constant while absolute intensities of spectra varied significantly from one to the other. Polarized and unpolarized spectra also showed similar shapes (Figure 3). However, there were minor deviations from this generalization; for example, there were significant variations in shoulder peak intensities at 3,415 and $3,400 \mathrm{~cm}^{-1}$ depending on the crystal orientation.

We examined the similarity of the spectra shapes by plotting the ratios of peak intensities at 3,565, 3,528, and $3,390 \mathrm{~cm}^{-1}$. If the spectra obtained for two orthogonal orientations are symmetric, then the plot of the intensity ratios for one orientation against the other should result in a perfect correlation. Figure 5 shows the intensity ratios of (a) the 3,565 and $3,390 \mathrm{~cm}^{-1}$ bands and (b) the 3,565 and $3,628 \mathrm{~cm}^{-1}$ bands. The good correlation (Figure $5 \mathrm{a}$ ) demonstrates that the intensities of the 3,565 and $3,390 \mathrm{~cm}^{-1}$ bands vary proportionally with respect to the orientation. The correlation improved for an unpolarized spectra against one of the polarized orientations, which was probably due to the averaging effect by the unpolarized photon vector.

Infrared light absorption in the range of 3,200 to 3,700 normally represents the interaction of photons with $\mathrm{OH}$ stretching vibrations. Therefore, the variation in IR absorption depends on the angle between the photon vibration vector and the stretching vibration vector. If the orientations of the crystallographically distinct $\mathrm{OH}$ bonds corresponding to the 3,565 and 3,390 $\mathrm{cm}^{-1}$ bands are parallel in the TiChu crystal, there should be a perfect correlation between the intensity ratios. However, Figure 5a shows moderate scatter around a general correlation, which suggests that these $\mathrm{OH}$ bond orientations deviate from the parallel. This deviation from the parallel was not significant enough to invalidate the correlation of Figure $5 \mathrm{a}$. It should also be noted that the correlations of peak intensity ratios for other vibration bands were weak or nonexistent (Figure $5 b$ ). 


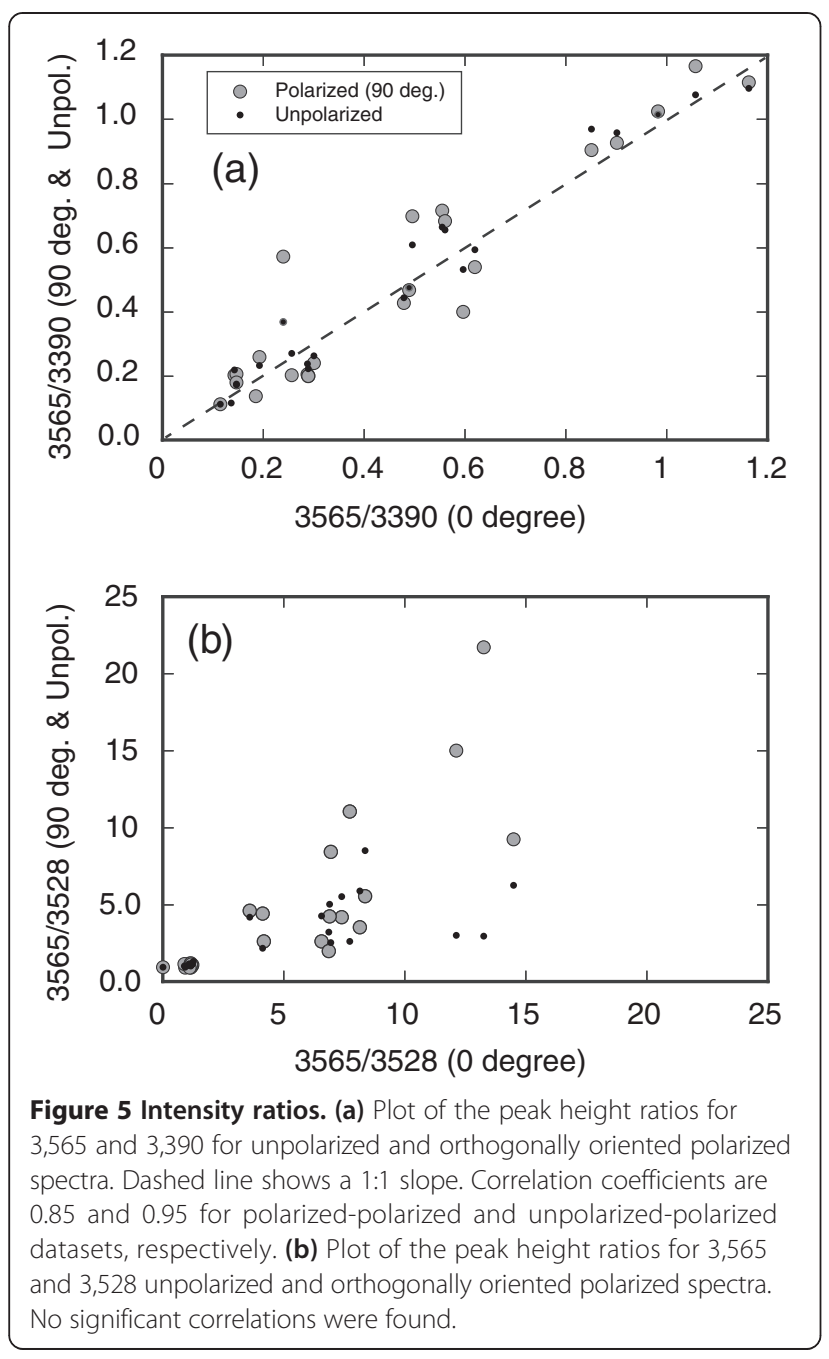

\section{Correlation of IR spectra and chemical composition}

Because each IR absorption band shown here represents an $\mathrm{OH}$ bond in a certain crystallographic site, inherent relationships can be expected between the shape of the IR spectra and the chemical composition, especially in the case of OH-F exchange in TiChu. A detailed study of oriented clinohumites should enable the exact nature of OH-F substitutions to be identified, as well as the site preferences for these elements. The linear relationship between the intensity ratio of 3,565/3,390 and $\mathrm{F}$ abundance (Figure 6) implies a near parallel $\mathrm{OH}$ bond orientation. Furthermore, because the intensity ratio of 3,565/3,390 was more or less independent of the orientation, the ratio can be used to quantitatively calibrate the correlation between the shape of the IR spectrum and the F abundance.

The spectroscopy results show that the shape and strength of the FTIR spectrum of TiChu is sensitive to the $X_{\mathrm{F}}$ value $\left(X_{\mathrm{F}}=\mathrm{F} /(\mathrm{F}+\mathrm{OH})\right.$ in atoms per formula unit). A robust correlation was present between $\mathrm{F}$ wt.\% and the unpolarized intensity ratio of 3,565/3,390 bands

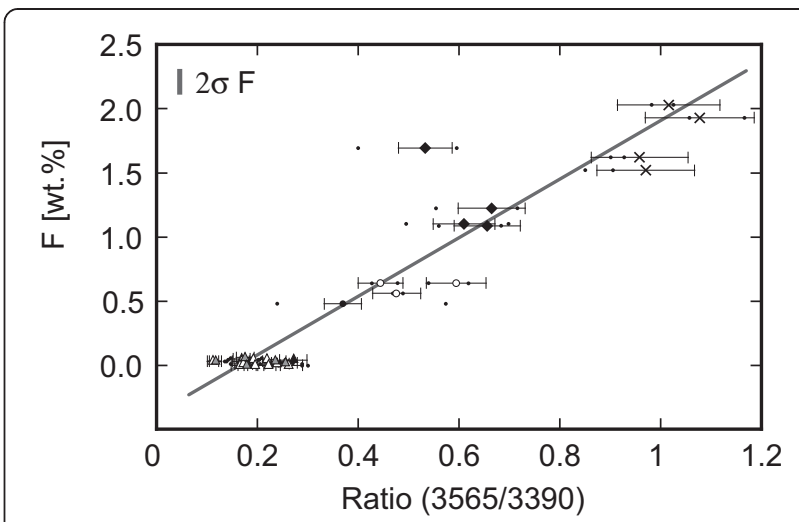

Figure 6 Plot of the $F$ wt.\% versus 3,565/3,390 intensity ratio showing a strong correlation between peak height ratios (i.e., the spectra shape) and $\mathrm{F}$ concentration. The linear regression resulted in $\mathrm{F}(\mathrm{wt} . \%)=-0.36+2.3 R_{3,565 / 3,390}$ where $r^{2}=0.938$. Small dots are the polarized spectra data, and large symbols are the unpolarized data with symbols corresponding to the key in Figure 1.

$\left(R_{3,565 / 3,390}\right.$; Figure 6). Using this correlation, it is possible to estimate the approximate composition of clinohumite from FTIR spectra. The weighted regression in Figure 6 gives the following formula:

$$
\mathrm{F}[\mathrm{wt} . \%]=-0.36+2.3 \mathrm{R}_{3,565 / 3,390,} \text { where } \mathrm{r}^{2}=0.938 .
$$

The uncertainties of the regression are not reported here because the intention of this study was to demonstrate the presence of a composition-spectra correlation. This formula is useful in estimating F content upon detection of clinohumite by spectroscopic methods. It is clear that a calibration based on Raman spectra would be more versatile in natural sample applications.

\section{Application of the correlation to complex natural situations}

Fluorine abundance in solid materials can often be measured using an electron microprobe, as in the case of the large TiChu crystals in this study, but accurate F measurements by an electron microprobe are not routine and require some developments (Ottolini et al. 2000). Estimation of the chemical composition from IR spectra is probably a useful alternative for cases such as complex intergrowths of TiChu with olivine. Clinohumite crystals in olivine can occur as lamellae at scales ranging from several hundred nanometers to several tens of micrometers (Wirth et al. 2001; Mosenfelder et al. 2006b; Berry et al. 2007). Because a higher F abundance stabilizes TiChu at higher temperatures (Evans and Trommsdorff 1983), the identification of such lamellae in olivines can provide new information about the volatile element sink that is transported deep into the mantle.

Published FTIR spectra of F-rich TiChu from Dabie Shan, China (Hermann et al. 2007) and those obtained 
here for F-rich TiChu from Cima di Gagnone (Figure 2) are similar. Accordingly, FTIR spectra may allow us to infer that relatively F-poor TiChu from the Almirez chlharzburgite formed at lower temperatures than F-rich ones from Dabie Shan or Cima di Gagnone. This grossly simplified conclusion can be made despite ignoring initial $\mathrm{F}$ abundances and activity in the respective protoliths, and it is supported by independent P-T estimations made in each of these localities.

Among recent reports on the hydrogen incorporation mechanisms in olivine, the presence of clinohumite-type $\mathrm{OH}$ defects has been proposed as one of the critical natural incorporation mechanisms (Miller et al. 1987; Berry et al. 2005; Mosenfelder et al. 2006b; Berry et al. 2007; Walker et al. 2007). Our IR characterization should not be applied to the investigation of olivine point defect structures because the reported IR spectra in olivine are suggestive of dissimilarities between $\mathrm{TiChu}$ structures and TiChu-like defects. For instance, forsterites synthesized under an $\mathrm{MgO}$ and $\mathrm{TiO}_{2}$ buffer (Berry et al. 2005) show stronger IR absorption peaks at 3,572 and 3,525 than around 3,415 to 3,390, whereas our results consistently showed stronger peaks around the 3,415 to 3,390 region than either of the peaks at 3,572 or 3,525 . In Berry et al. (2005), the 3,572 and 3,525 peaks are attributed to TiChu-like $\mathrm{OH}$-incorporating defects. We note that the TiChu $\mathrm{OH}$ stretching peaks are at 3,565 and 3,528 , offsets of -7 and $+3 \mathrm{~cm}^{-1}$ from that of the $\mathrm{OH}$ defect in olivine. Looking at the spectra qualitatively (Figure 1 in Berry et al. 2005), the defect peaks are similar to the clinohumite peaks, but these offsets are significantly beyond the uncertainty of the instrument. These disparities point to the fact that the casually termed 'titanian clinohumite-like defect' is structurally dissimilar to TiChu minerals apart from the fact that both have $\mathrm{Ti}$ in the sixfold coordinate site. Mosenfelder et al. (2006b) presents a similar conclusion based on the inconsistency of peak intensities found in experimental and natural olivine crystals with TiChu-like defects.

\section{Competing interests}

The authors declare that they have no competing interests.

\section{Authors' contributions}

The manuscript was written by KTK and verified for accuracy by all authors. CJG, JAPN, and VLSV collected the samples and provided all petrological information. Data acquisitions were done by KTK and CJG. MTGP provided crystallographic information of the sample. All authors read and approved the final manuscript.

\section{Acknowledgements}

This project was funded by the BQR grant from the Université Blaise Pascal Clermont Ferrand II and the Spanish Ministry of Science (MEC) grant CGL2009-12158 and CGL2012-32067. This work was carried out during the visiting professorship of CJG to the Laboratoire Magmas et Volcans, which was funded by OPGC - Université Blaise Pascal. This work was also supported by ANR SlabFlux, ANR09BLAN0338. This is Laboratory of Excellence ClerV olc contribution no. 100. JPAN is supported by HISLa-DR, Marie Curie Action under grant agreement PIOF-GA-2010-273017 from the European Union Seventh Framework Programme (FP7/2007-2013).

\section{Author details}

'Laboratoire Magmas et Volcans, Clermont Université, Université Blaise Pascal, Clermont-Ferrand 63038, France. 'Laboratoire Magmas et Volcans, CNRS UMR 6524, Clermont-Ferrand 63038, France. ${ }^{3}$ Laboratoire Magmas et Volcans, IRD M163, Clermont-Ferrand 63038, France. ${ }^{4}$ Instituto Andaluz de Ciencias de la Tierra (IACT), CSIC-UGR, Armilla, Granada 18100, Spain ${ }^{5}$ Géosciences Montpellier, Université Montpellier 2 \& CNRS, Montpellier 34095, France. ${ }^{6}$ Department Geología, Universidad de Jaén, Escuela Politécnica Superior, Linares 23700, Spain. ${ }^{7}$ Department Mineralogia y Petrología, Facultad de Ciencias, Universidad de Granada, Granada 18002, Spain.

Received: 14 November 2013 Accepted: 26 May 2014 Published: 26 June 2014

\section{References}

Bearth P (1967) Die Ophiolithe der Zone von Zermatt-Saas Fee. Beitraege zur Geologischen Karte der Schweiz NF 132. Kümmerly \& Frey, Bern

Berry A, Hermann J, O'Neill HSC, Foran GJ (2005) Fingerprinting the water site in mantle olivine. Geology 33:869-872

Berry AJ, O'Neill HSC, Hermann J, Scott D (2007) The infrared signature of water associated with trivalent cations in olivine. Earth Planet Sci Lett 261:134-142

Brugnatelli L (1904) Über den titanolivin der umgebung van chiesa in Val Malenco; ein beitrag zur kenntnis des titanolivin. Z Kristallogr Mineral 39:209-219

Damour M (1879) Note sur le peridot titanifère de Zermatt en Valais. Bulletin de la Societe Francaise de Mineralogie et de Cristallographie 2:15

De Quervain T (1938) Zur kenntnis des titanklinohumites (titanolivine). Schweiz Mineral Petrogr Mitt 18:591-604

Engi M, Lindsley DH (1980) Stability of titanian clinohumite: experiments and thermodynamic analysis. Contrib Mineral Petrol 72:415-424

Evans BW, Trommsdorff V (1983) Fluorine hydroxyl titanian clinohumite in Alpine recrystallized garnet peridotite: compositional controls and petrologic significance. Am J Sci 283A:355-369

Frost RL, Palmer SJ, Bouzaid JM, Reddy BJ (2007) A Raman spectroscopic study of humite minerals. J Raman Spectros 38:68-77

Fujino K, Takeuchi Y (1978) Crystal chemistry of titanian chondrodite and titanian clinohumite of high-pressure origin. Am Mineral 63:535-543

Garrido CJ, López Sánchez-Vizcaíno V, Gómez-Pugnaire MT, Trommsdorff V Alard O, Bodinier J-L, Godard M (2005) Enrichment of HFSE in chloriteharzburgite produced by high-pressure dehydration of antigorite-serpentinite: implications for subduction magmatism. Geochem Geophys Geosyst 6: doi:10.1029/2004GC000791

Hermann J, Fitz Gerald J, Malaspina N, Berry A, Scambelluri M (2007) OH-bearing planar defects in olivine produced by the breakdown of Ti-rich humite minerals from Dabie Shan (China). Contrib Mineral Petrol 153:417-428

Kitamura M, Kondoh S, Morimoto N, Miller GH, Rossman GR, Putnis A (1987) Planar OH-bearing effects in mantle olivine. Nature 328:143-145

Kurosawa M, Yurimoto H, Sueno S (1997) Patterns in the hydrogen and trace element compositions of mantle olivines. Phys Chem Miner 24:385-395

López Sánchez-Vizcaíno V, Trommsdorff V, Gómez-Pugnaire M, Garrido C, Müntener O, Connolly J (2005) Petrology of titanian clinohumite and olivine at the high-pressure breakdown of antigorite serpentinite to chlorite harzburgite (Almirez Massif, S. Spain). Contrib Mineral Petrol 149:627-646

Matsyuk SS, Langer K (2004) Hydroxyl in olivines from mantle xenoliths in kimberlites of the Siberian platform. Contrib Mineral Petrol 147:413-437

McGetchin TR, Silver LT (1970) Compositional relations in minerals from kimberlite and related rocks in the Moses Rock dike, San Juan County, Utah. Am Mineral 55:1738-1771

Miller GH, Rossman GR, Harlow GE (1987) The natural occurrence of hydroxide in olivine. Phys Chem Miner 14:461-472

Möckel JR (1969) Structural petrology of the garnet peridotite of Alpe Arami (Ticino), Switzerland. Leides Geologische Mededdelingen 42:61-130

Mosenfelder JL, Deligne NI, Asimow PD, Rossman GR (2006a) Hydrogen incorporation in olivine from 2-12 GPa. Am Mineral 91:285-294

Mosenfelder JL, Sharp TG, Asimow PD, Rossman GR (2006b) Hydrogen incorporation in natural mantle olivines. In: Jacobsen SD, van der Lee S (eds) Earth's deep water cycle. American Geophysical Union, Washington, D.C., pp 45-56 
Moune S, Sigmarsson O, Thordarson T, Gauthier PJ (2007) Recent volatile evolution in the magmatic system of Hekla volcano, Iceland. Earth Planet Sci Lett 255:373-389

Ottolini L, Cámara F, Bigi S (2000) An investigation of matrix effects in the analysis of fluorine in humite-group minerals by EMPA, SIMS, and SREF. Am Mineral 85:89-102

Ribbe PH (1979) Titanium, fluorine, and hydroxyl in the humite minerals. Am Mineral 64:1027-1035

Satish-Kumar M, Niimi N (1998) Fluorine-rich clinohumite from Ambasamudram marbles, southern India: mineralogical and preliminary FTIR spectroscopic characterization. Mineral Mag 62(4):509-519

Scambelluri M, Rampone E, Piccardo GB (2001) Fluid and element cycling in subducted serpentinite: a trace-element study of the Erro-Tobbio highpressure ultramafites (Western Alps, NW Italy). J Petrol 42:55-67

Scambelluri M, Muntener O, Ottolini L, Pettke TT, Vannucci R (2004) The fate of B, $\mathrm{Cl}$ and $\mathrm{Li}$ in the subducted oceanic mantle and in the antigorite breakdown fluids. Earth Planet Sci Lett 222(1):217-234

Thompson JB (1978) Biopyriboles and polysomatic series. Am Mineral 63:239-249 Trommsdorff V, Evans BW (1980) Titanian hydroxyl-clinohumite formation and breakdown in antigorite rocks (Malenco, Italy). Contrib Mineral Petrol 72:229-242

Veblen DR (1991) Polysomatism and polysomatic series. Am Mineral 76:801-826

Veblen DR (1992) Electron microscopy applied to nonstoichiometry, polysomatism, and replacement reactions in minerals. In: Buseck PR (ed) Minerals and reactions at the atomic scale: transmission electron microscopy, vol 27, Mineralogical Society of America. Washington, D.C., pp 181-230

Walker AM, Hermann J, Berry AJ, O'Neill HSC (2007) Three water sites in upper mantle olivine and the role of titanium in the water weakening mechanism. J Geophys Res 112, B05211

Wirth R, Dobrzhinetskaya LF, Green HW II (2001) Electron microscope study of the reaction olivine $+\mathrm{H} 2 \mathrm{O}+\mathrm{TiO}_{2}->$ titanian clinohumite + titanian chondrodite synthesized at $8 \mathrm{GPa}$, 1300K. Am Mineral 86:601-610

doi:10.1186/1880-5981-66-60

Cite this article as: Koga et al:: FTIR and Raman spectroscopy

characterization of fluorine-bearing titanian clinohumite in antigorite serpentinite and chlorite harzburgite. Earth, Planets and Space 2014 66:60

\section{Submit your manuscript to a SpringerOpen ${ }^{\circ}$ journal and benefit from:}

- Convenient online submission

- Rigorous peer review

- Immediate publication on acceptance

- Open access: articles freely available online

- High visibility within the field

- Retaining the copyright to your article

Submit your next manuscript at $\gg$ springeropen.com 